Journal of Education and Vocational Research

Vol. 2, No. 1, pp. 1-3, July 2011 (ISSN 2221-2590)

\title{
Review of Harvard Business Review: McKinsey Award Winners
}

\section{Book Review}

\author{
Reviewed by: Shiva Kumar Srinivasan \\ Institute of Planning and Management (IIPM), Chennai \\ sksrinivasan2008@hotmail.com
}

The articles published in the Harvard Business Review are usually considered to be the best in the theory and practice of management; the best of these best articles is awarded the annual McKinsey prize that is sponsored by the McKinsey Foundation for Management Research. This anthology of essays is a representative anthology of such essays from Harvard Business School Press. Almost all the contributors to this anthology are leading dons at Harvard Business School, or at eminent schools like London Business School, Ross Business School, or the University of Chicago. What these essays have achieved in the theory and practice of management is difficult to summarize in a few words; but, nonetheless, we can safely surmise that they will continue to be as influential in the years to come as they have been in the recent past. There are eight articles in this anthology: the dates of publication comprise the period from as early as 1967 to as recently as 2005. What this period demonstrates is that work in management doesn't date as easily as it is commonly believed, but continues to remain useful for a considerable period of time. While all the areas collected in this anthology are of general interest, they comprise a number of specific areas like general management, decision making, competitive strategy, strategy and technology, and globalization. Needless to say, this anthology of essays will be useful to not only experts in these areas, but also to students in graduate programs in business school who are on the look-out for role models in management thought. It is therefore important to read these essays both in terms of form and content and think-through their stylistic dimensions as well. This is all the more important if we want to understand how leading theorists of management differentiate their cognitive style in what is obviously an over-crowded field.

Most regular readers of HBR, and those who have studied in a business school, will be familiar with many if not all of these essays. So the goal in this review is not to summarize the main arguments in all these essays, but to situate them instead within the domain of general management, and ask, whenever possible, what is that makes these essays special. I will not review these essays however in their exact sequence of appearance, but sort them instead into specific sets of theoretical concerns starting with strategy before going on to address problems of organizations and organizational leadership as problems of general management. The most important set will be that of competitive strategy; the representative essay here is that of Michael Porter's well-known essay from 1979, which discusses 'how competitive forces shape strategy'. This is a highly anthologized piece and a staple of strategy textbooks: what makes this essay unique at this point in time is the fact that it not only provided an important cognitive tool for theorists of strategy, but also made it possible to introduce the contextual and situational dimensions of a firm (which is the locus of competition). What Porter teaches us from a structural point of view is that competitive behavior in firms is often shaped by what happens outside the firm. Strategy, and strategic choices, to put it simply, cease to be a matter of internal introspection on the part of the key decision maker, but is determined instead by competitive forces that are not within the control of the firm. It becomes instead something that is worked out within a competitive arena (almost like a spectator sport) with barriers to entry and exit, and requires a wholesome interest in the analysis of industries, and how specific firms relate to the industries to which they belong, or to which they are affiliated. While discussions will continue on whether or not Porter has identified all the relevant forces, and on whether this framework requires supplements, the significance of this framework for an analysis of the rudiments of competitive strategy has never been in doubt. This framework is possibly the one thing about Porter's work that almost everybody with some exposure to the management curriculum will have some understanding of. This is also a framework that has determined the way both business academics and strategy consultants think within the domain of competitive strategy. All attempts to go beyond Porter or 
change the basic orientation of strategy have been more of an attempt to change the topic rather than negate the analytic tools available in competitive strategy.

The 1990 essay by C. K. Prahalad and Gary Hamel on core competence is not a negation of competitive strategy, but an attempt to ask a simple question from a resource-based point of view. What is the relationship between being in a business and having a core competence in a particular area? The significance of this question relates to the fact that competencies are more enduring than businesses. And, furthermore, as Peter Drucker was fond of pointing out, many firms are not sure what business they are in. This is all the more reason that they should at least identify what competencies, if any, are available within the firm. Identifying competencies correctly will make it possible for a firm to reinvent itself since they can be applied in a number of emerging business contexts. What Prahalad and Hamel teach us then is the importance of differentiating between what a firm is what a firm does, and what a firm is good at doing. Once there is clarity on these matters, a firm is equipped to not only compete effectively, but become more proactive in shaping its own future. It will stop waiting for the future to happen and be on the lookout for innovative contexts in which it can deploy its competencies. The examples of competencies cited in this essay are often forms of technology or technological applications like miniaturization. Understanding the role that technology plays in the context of strategy then is important because technology can disrupt the business model in place.

Joseph Bower and Clayton Christensen therefore argue in their 1995 essay that not only do technologies change constantly, but that the consequences of these changes must be understood within the strategic framework that is built into a business. While firms are willing to invest in the technology that their current customers demand, they often do not understand what sort of technology will be needed to hold on to the customers with whom they will want to do business with in the future. Neither the firm nor its mainstream customers will be able to anticipate or understand the role that disruptive technology will play in their future. So it is often the case that mainstream customers will reject new technology if it does not conform to their current specifications. It is therefore important for a firm to be willing to spin-off new technologies that can not only be developed outside the circuit of its mainstream customers, but within a different organizational structure as well. This is not only an important essay from an HBR point of view, but helped to generate the disruptive technology framework that Christensen and his associates have spent the better part of their careers working on. An important strategic takeaway from this framework is that it is not necessary for a superior technology to get ahead from a business point of view. Most disruptive technology is about reducing the complexity of innovative technology by reducing or simplifying its product attributes in order to make it more accessible to customers. What works from the advanced technology point of view may be at odds with the requirements of the business. This is not just a counter-intuitive form of strategy, but heresy given the default assumption that the better the technology, the greater its relevance to the business model of the firm. Likewise, Pankaj Gehmawat argues that regional growth strategies can disrupt the belief that only global leadership is worth aiming for or that there is a direct way of quickly becoming global. Both in the case of disruptive technology and in Gehmawat's argument, there is an attempt to reduce the scope of the strategic endeavor that goes against the grain of contemporary strategic theory. Gehmawat argues from international trade data that 'trade across regions' is probably less important than 'trade within regions' as the driver of economic prosperity and vitality. What Gehmawat means by regions is linked to the notion of spatial proximity: 'the extent and persistence of regionalization in economic activity reflect the continuing importance not only of geographic proximity but also of cultural, administrative, and... economic proximity'.

This notion of regional proximity is the case with industries as well and not just trade. Gehmawat argues that there has been a continual increase in industry concentration as measured by the Herfindahl index: what is thought to be global competition 'is playing out at a regional level'. The industrial clustering of firms happens then not only at the level of urban units, but in terms of entire regions. It is therefore important for firms to determine the 'regional strategies' that will help them to eventually attain 'global leadership'. Gehmawat's essay of 2005 then is an attempt to set out precisely such a disruptive strategy and the different steps that a firm must follow to attain global leadership. While the essays discussed above constitute the strategic frameworks required to be competitive, it is also important to understand the interpersonal and organizational contexts that mediate the everyday life of a business. So, for instance, the difficult question of whether strategy follows (organizational) structure or vice versa demands that we attend to the problem of organizational design and what sort of managerial and leadership strategies can help firms to accrue a 
competitive advantage. Peter Drucker argues in his essay of 1974 that there is a need for new 'templates' to design organizations. While the classical models continue to be useful in the contexts of automobile manufacturing, they may not be readily applicable in the context of the knowledge-based service industries or even in forms of manufacturing which deal with a range of products with complex design specifications for each of these. As services begin to increase their contribution to the over-all GDP, new forms of organizational design will be required to both facilitate and formalize their contribution. It is time then to rethink the basic principles of organizational design so that contemporary firms do not become antiquated forms of social organization, but dynamic responses to the forms of social production that constitute the advanced economies of our time.

And, finally, the three essays on managers by Edward Wrapp (1967), Rosabeth Kanter (1979), and John Gabarro and John Kotter (1980) throw light on what continue to remain the perennial challenges of leading organizations effectively. The essence of these essays is to move away from the textbook notion of the manager that dominated the literature at one point in time to the empirical representations of the manager. The main goal is to track what managers actually do given the innumerable interruptions that they have to live with rather than depict them as strategists who can think uninterruptedly. These essays also argue that managers must not isolate themselves from the operational demands of their jobs, but must learn to incorporate the excitement generated by these situations into the fabric of their strategic approaches for the firm. It is also important for managers to recognize the need for power to do their work effectively; powerlessness is not necessarily a virtue. What matters is how effectively power is deployed to further the legitimate interests of the firm rather than fight shy of its existence or the need for it on the part of managers who can no more function without power as an electrical gadget is likely to work without being plugged into the power system. While power is thought of as flowing from the top in administrative terms, communication between the boss and his employees goes both ways. Just as there is 'downward' communication, there is also something known as 'upward' communication. It is not only the manager who must manage his team, the members of the team must also manage the manager or the team leads. What this means is that the task of interpersonal organization in managerial situations is not to be understood only as the responsibility of the manager; but, increasingly, in flat organizations, as a mutual responsibility. While some of these ideas may seem obvious, that is because we have forgotten how different or unusual these ideas and suggestions for improvement were just a few years ago when they were either first articulated or formalized in these award winning essays. These suggestions however have passed on to the realm of lived experience and reading these essays is an opportunity to work-through their intellectual genealogy in the theory and practice of management. 